\title{
Organizational Culture and Work Environment: Its Effect on Teachers Organizational Citizenship Behavior (OCB)
}

\author{
Arindi Nurhidayah ${ }^{1}$, Nurhattati $^{2}$, Matin $^{3}$
}

\begin{abstract}
The objective of this research is to study information about the effect of organizational culture and work environment on the organizational on the organizational citizenship behavior of teacher elementary school in subdistrict Pulo Gadung. The study used a survey method with path analysis tecniques. The process of teacher elementary school in Pulo Gadung subdistric data collections is done by using the questionnaire as a research instrument in the study of was selected as the unit of analysis with a sample 384 people is determined by random techiques. The results snow: Firstly, there is the influence of organizational culture by organizational citizenship behavior; Secondly, there is the influence of work environment by organizational citizenship behavior; Third, there is the influence of organizational culture on work environment.
\end{abstract}

Keywords: organizational culture, work environment, and organizational citizenship behavior

\section{Introduction}

The global competitiveness of Indonesia's education is constrained by the priorities of national education development without looking at the competent human resources in the field of education. Teachers as the driving force who is the spearheads of education become the benchmark of an educational success.

Some countries have introduced the professional standards for teachers and principals, for example in the USA where the National Board of Professional Teacher Standards has developed assessment standards and procedures based on the five basic principles (Syarief Hidayat, 2012: 10) i.e., teachers dedicated to the students and their learning, the teacher knows the teaching materials they teach and how to teach the material to the students, the teacher is responsible for managing and monitoring the students' learning, the teacher thinks systematically about what they do and learn from experience, the teacher is a member of the learning community .

The obligation of teachers is to serve education, especially in the schools, through teaching, educating and training, to educate the life of the nation, preparing our nation's generation to be able to live in global competition. To carry out a duty such as teaching, educating, and training are not the easy things, it requires an attitude of volunteerism and caring in the person of a teacher.

There are several problems that exist in Pulo Gadung District, such as the low of teacher's competence, lack of supervision of principals, the low of teacher creativity, and the teacher's care in Pulo Gadung District is still lacking, even though the teachers have understood about the main task and function (tupoksi) but they still have less concern with. Teachers' responsibilities in teaching are still low, where the teacher does not prepare materials and lesson plans, and evaluation materials.

The volunteerism of teachers in carrying out tasks is still questionable. A teacher's voluntary behavior is very important, because it is part of the behavior that makes up a performance. Robbins and Timothi A. Jugde (2011: 599) explain that there are three main behaviors that shape performance, namely, "task performance, citizenship and counter productivity."

Another factor that affects voluntary attitude is the organizational culture and work environment. In addition, factors that can affect the attitude of volunteering such as leadership attitudes, working period, personality and mood of the members of the organization. The culture of the organization should be well developed, because if an organization has a strong culture, then the members of the organization will give great loyalty to the work. Good organizational culture will show good organizational performance. Organizational culture affects teachers' voluntary attitudes. In organizational culture there are values and shared assumptions of an organization in the school environment that will affect the state of the school every day.

In global journal of business research entitled "Influence of organizational culture on OCB: A Study Three-Sector Study" stated that : "they represent 'extra effort' by employees that is nonetheless essential for the effectiveness of the organization, especially where organizational performance is dependent on the interconnectedness and social networks of its people. Though it is not formally recognized by the reward system of an organization, it has the potential to contribute towards improving efficiency and effectiveness of an organization leading to increased competitive advantage"

The journal explains that volunteer behavior is an 'extra effort' done by employees that are important and play a role in improving organizational effectiveness, especially organizational performance depends on the linkage and social networking community. Although, it is not formally recognized by the organization's reward system, it has the potential to contribute to improving the efficiency and effectiveness of an organization that leads to increased competitive advantage. 


\section{International Journal of Science and Research (IJSR) \\ ISSN (Online): 2319-7064}

Index Copernicus Value (2016): 79.57 | Impact Factor (2015): 6.391

Then in International Journal of Education Research "Factors Influencing Organizational Citizenship Behavior and Academic Motivation In The Classroom "Explains that OCB behavior, "employees affiliated with organizations sometimes display behaviors that are not aligned to organizational rewards. It is not a strange phenomenon for co-workers to assist each other by filling in, voluntarily when an absence arises or offer to help another co-worker in accomplishing his/her duties and responsibilities. These behaviors, overtime contribute to the smooth running of departments, work units, work team and ultimately the productivity of the organization"

In "Factors Influencing Organizational Citizenship Behavior and Academic Motivation in the Classroom" journal explains that employees in organizations sometimes display behaviors that are not in line with what the organization provides. It is not hard for co-workers to help each other by filling in, voluntarily when there is a friend's absence to help other colleagues in completing their duties and responsibilities. OCB behavior contributes to the smooth running of each work unit, teamwork, and ultimately improves performance within the organization.

Organizational culture that illustrated in public schools is not good enough. Teachers still follow the values that are not good in the education process. Organizational culture is suspected to have an influence on teacher volunteer behavior in work. The teacher's voluntary behavior is more than standardized behavior and aims to maximize the achievement of goals within the school organization, with indicators of helping fellow co-workers, serving the job, being responsible for duty, sportsmanship towards colleagues, and empathy towards the environment.

This study examines the direct effects of organizational culture on $\mathrm{OCB}$, the direct influence of the work environment on $\mathrm{OCB}$, and the influence of organizational culture on the work environment, with the subject of research of elementary school teachers in Pulo Gadung District.

\section{Literature Review}

Colquitt, Le Pine, and Wesson (2014: 41), define OCB "as voluntary employee activities that may or may not be rewarded but that contribute to the organization by improving the overall quality of the setting in which work takes place". OCB the voluntary activity of employees though may not be appreciated but contributes to the organization by improving the overall quality of the rules that take place in the workplace. Meanwhile Paul E.Spector (2000: 235) defines OCB, "is generally defined as behavior that goes beyond the formal requirements of the job and is beneficial to the organization." In this case OCB is a behavior that goes beyond the requirements of the job and has great benefits in the organization.

Furthermore, Stephen P. Robbins and Timoty A. Jugde (2011: 60) define OCB, "as discretionary behavior that is not part of an employee's formal job requirements but nevertheless promotes the effective functioning of the organization." Successful behavior is the behavior of the employees who are discretionary and are not part of the employee's formal employment task that has been determined but, the OCB's behavior can improve the functionality in the organization effectively.

Schermerhorn, Osbron, Uhl-Bien and Hunt (2012: 348) define organizational culture "organizational culture is a joint system of action, values, and beliefs that develop within an organization and become a belief that exists in the behavior of members of the organization. Furthermore according to Schermerhorn (2013: 497) "the organizational culture refers to a system of shared meaning held by members that distinguishes the organization from other organizations ". The described organizational culture is a system of shared meanings shared by members of organizations that differentiate organizations from other organizations.

On the other hand, Edgar Schein (2013: 180) describes organizational culture, "however, argues that culture should be reserved for a" deeper level of basic assumptions, values, and beliefs"that become shared and taken for granted as the organization continues to be successful". Edgar explains that organizational culture is how the culture is derived from the opinions of organizational members to create "the deeper basic assumptions, values, and beliefs "that are the common goals and can be accepted by organizational members to achieve success within the organization.

According to Schaubroeck in Erwin Locke (2009: 183) the work environment, "is unperturbed to the employers of low perceived efficacy to manage them." The work environment is the condition or place owned by employees in the organization, which has the benefit of making better thinkers in the work. Furthermore, Ian Rothmann and Cary Cooper (2008: 3) define the working environment, "as one in which all the physical". According to Ian, the work environment is interpreted as a place that is only physical in the organization. On the other hand, Joan E. Pyness (2009: 110) defines work environment as supportive and nurturing and contribution that are appreciated. The working environment is very supportive thing and it makes great contribution in work.

\section{Research Methodology}

The research method used in this research is survey method, using quantitative approach. This research was conducted at the elementary school in Pulo Gadung District, East Jakarta and this research has 384 population, and 196 people as the sample. The sampling usedrandom sampling technique, and the data analysisused path analysis technique.The study used path analysis to determine the influence between variables tested in accordance with the causal model that formed. Exogenous variables organizational culture (X1) and work environment (X2) is a variable that is considered to affect the endogenous variable (X3).Prior to the research conducted, test instrument was conducted first to comprehend the validity and reliability of the instrument The results will be used for research instruments and data retrieval. Data analysis used include: 1) description of data, 2) prerequisite test of normality analysis, 3) path analysis

Volume 6 Issue 12, December 2017 


\section{International Journal of Science and Research (IJSR) ISSN (Online): 2319-7064}

Index Copernicus Value (2016): 79.57 | Impact Factor (2015): 6.391

including: model analysis, hypothesis testing and determination of level of influence.

The data collection instruments for each variable. The research instrument that will be used by the elementary school teacher in Pulo Gadung District, East Jakarta in the form of questionnaires before being used to collect research data, firstly tested the validity and reliability calculation. Validity test is done to comprehend how far the accuracy and accuracy of a measuring instrument in performing the measuring function, while the calculation of reliability to comprehend the extent to which the measuring instrument can give relative results is no different when re-measured against the same symptoms at different times.

The Questionnaires of elementary school OCB teachers in District of Pulo Gadung, East Jakarta.

The instrument was then developed by researchers and has been tested for its validity and reliability. Measurement of instrument validity was using product moment correlation formula. Measurement of instrument reliability was usingCronbach alpha formula. The experimental results show that from 30 OCB teacher questions, there are 30 valid items with OCB teacher reliability calculation equal to 0.90 , organizational culture variable are 35 items of question and there are 29 valid items with calculation of organizational culture instrument reliability equal to 0.91 , from work environment variable is 35 itemsof question and there are 30 valid items with calculation of working environment instrument reliability equal to 0.92 .

\section{Results and Discussion}

From the testing result, the overall hypothesis between variables $\mathrm{X} 1, \mathrm{X} 2$, and $\mathrm{X} 3$ can be summarized through the table below:

Table 4.13: Summary of Proposed Hypothesis Testing Result

\begin{tabular}{|c|c|c|c|}
\hline \multirow{2}{*}{$\begin{array}{c}\text { Direct } \\
\text { influence }\end{array}$} & \multicolumn{2}{|c|}{ Statistical testing } & $\mathrm{t}_{\text {table }}$ \\
\cline { 2 - 4 } & Path Coefficient & $\mathrm{t}_{\text {count }}$ & 0,01 \\
\hline $\mathrm{X}_{1} \mathrm{X}_{3}$ & 0,436 & $7,369^{* *}$ & 2,60 \\
\hline $\mathrm{X}_{2} \mathrm{X}_{3}$ & 0,365 & $6,169^{* *}$ & 2,60 \\
\hline $\mathrm{X}_{1} \mathrm{X}_{2}$ & 0,467 & $7,032^{* *}$ & 2,60 \\
\hline
\end{tabular}

**Description is very significant

Based on the overall path coefficient analysis, it can be summarized the path analysis model as follows:



Figure 4.7

\section{Hypothesis End Lines Analysis Model}

From the first hypothesis, there is a direct positive influence of organizational culture to OCB. From the first hypothesis testing results, it can be concluded that there is a direct positive influence of organizational culture on OCB. From the calculation results, it obtained correlation coefficient $\mathrm{r} 13$ $=0,606$ and path coefficient of p31 $=0.436$. This implies that organizational culture has an immediate effect on OCB.

The results of this study are also similar in Global Journal of Business Research entitled "Influence of Organizational Culture on Organizational Citizenship Behavior" it stated that, "it was hypothesized that each variable in Organizational Culture will significantly influence the Organizational Citizenship Behavior across all Organizations and also for each of the Organization. This hypothesis was accepted. It was evident from the analysis that each variable was significantly correlated to the other variable, across all Organization."

The above explanation, that has hypothesized every variable in organizational culture, has a significant effect on volunteer behavior in organization and also for each organization. The research proved that there is a significant correlation. Furthermore, from the results of research inInternational Journal of Business, Humanities and Technology entitled "Influence Analysis of Organizational Culture, Organizational Commitment Job and Satisfaction Organizational Citizenship Behavior (OCB) Toward Improved Organizational Performance", it stated that organizational culture has a positive effect on organizational performance Parameter estimation between organizational culture on organizational performance positive $b$ showed significant results with values $\mathrm{CR}=2.928 ; \mathrm{CR} \geq 2.00$ with a significance level of $0.05(5 \%)$. Thus hypothesis 6 acceptable means to positively influence organizational culture significantly to organizational performance in this study empirically proven.This suggests that organizational culture has a positive influence on organizational performance that is part of OCB. Result of research between organizational culture on positive organizational performance proved significant result with values $\mathrm{CR}=$ 2,928 ; $C R \geq 2.00$ with a significance level of $0.05(5 \%)$. Thus, the hypothesis can be accepted to positively affect the organizational culture significantly to organizational performance in this research proved empirically. The results of this study are also in line with some experts among them, according to Colquitt LePine and Welson (2008: 557), "organizational culture as the shared social knowledge within the organizational of the rules, norms, and values that shape the attitudes and behavior of its employees, "organizational culture in school as a social knowledge within the organization regulates some rules, norms, and values that can shape the attitudes and behavior of teachers in their daily lives."

Thus, it can be concluded when the organizational culture strengthens the OCB will increase, based on the description it is clear that organizational culture has a direct positive influence on OCB.

In the second formulated hypothesis, there is a direct positive effect of work environment on OCB. From the results of the second hypothesis testing can be concluded that there is a direct positive influence of work environment to OCB. From the results of the second hypothesis testing, it can be concluded that there is a direct positive influence of 


\section{International Journal of Science and Research (IJSR) \\ ISSN (Online): 2319-7064}

Index Copernicus Value (2016): 79.57 | Impact Factor (2015): 6.391

work environment against OCB. From the calculation results, it obtained correlation coefficient r23 $=0,569$ and the coefficient of the path of $\mathrm{p} 23=0.365$. This implies that the work environment has an immediate effect on OCB. The results of this study also proved by research in the International Journal of Business, Economics and Law, stated that, "this study contributes in assessing the factors that increase the organizational citizenship behavior of internal auditor. Organization should enhance empowering internal auditor through work environment. There should be a regular evaluation of work environment to monitor and evaluate physical work condition, communication climate, and how fit rules and procedures with organization strategies. This is aimed at enhancing internal auditor psychological empowerment and performance". The studies show that to improve voluntary behavior within organizations. Organizations must enhance empowerment through work environments. There should be a regular evaluation of the work environment to monitor and evaluate the working conditions of the physical, communicative climate, and how appropriate rules and procedures with organizational strategy. It aims to improve the performance of organizational members. Then in International Journal of Independent Research and Studies-IJIRS entitled "Factors of Workplace Environment that Affect Employees Performance: A Case Study of Miyazu Malaysia" stated that "in this research study a mixed of results had been gained. This result clarify the factor of workplace environment that could affect the employees' performance at Miyazu (Malaysia) Sdn. Bhd. Based on the past research study by Chandrasekar (2011), he predicted that there are several factors that affecting the employees' performance. The three independent variables in this research study also being included in Chandrasekar's research study which influenced the employees' performance. The journal explained that the previous research has results that make clear the workplace environment can affect employee performance. This is proved by the previous research and the theory put forward by Stephen P. Robbins and Timothy A. Judge, they stated that "an organizations environment includes outside institutions or force that can affect its performance, such as suppliers, costumers, competitors, government, regulatory agencies and public."That the work environment can affect the performance of teachers in schools formed in an OCB behavior. Therefore, the working environment accuracy that is conducive needed in the work environments of the teachers in elementary schools in Pulo Gadung District. Thus, when the work environment is precise and conducive the OCB will increase, based on the description, it is clear that the work environment has a positive direct influence on OCB.

In the third formulated hypothesis, there is a direct positive influence of organizational culture on the work environment, it can be concluded that there is a direct positive influence of organizational culture on the work environment. From the results of first hypothesis testing, it can be concluded that there is a direct positive influence of organizational culture on the work environment. From the calculation results, it obtained correlation coefficient $\mathrm{r} 12=0,467$ and coefficient value of path equal to $\mathrm{p} 21=0,467$. This implies that organizational culture has a direct influence on the work environment. In the journal "The Influence of
Organizational Culture on Organizational Learning, Worker Involvement and Worker Productivity", "this result is confirmed by O' Relly et al. (2000) as they hold that culture and environment are the good predictors of employees' success as a good culture and a good working environment requires that organization have the following: encourage fun in the workplace; create a good physical place to work including needed resources to do the job right; establish a mentoring program; actively promote positive relationship among co-workers; build an atmosphere of trust and fairness; and put employees on the organizations' balance sheet, to make them an essential part of the organizations' community an inclusive, extended-family relationship". From the results of the journal, it is clear that organizational and environmental culture is a factor of employee success, good culture and a good working environment require the organization to have the following: encouraging joy in the workplace; creating a good physical place to work including the resources needed to do the job properly; create mentoring programs; actively promote positive relationships among colleagues; build an atmosphere of trust and justice; and placing employees on the organization's balance sheet, to make it an important part of the organizational community as an inclusive family relationship and inclusive. This is also evidenced in the statement of Mc Shane, he states that there is an influence of organizational culture to the environment, "Subcultures, particularly counter cultures, potentially create conflict and dissension among employees, but they also serve two important functions. First, they maintain the organizations standard of performance and ethical behavior. Employees who hold counter cultural values are an important source of surveillance and critical revise of the dominant order. They encourage constructive conflict and more creative thinking about how the organization should interact with its environment. Organizational culture, as a norm prevailing in schools, affects the work environment, especially teachers in interacting and carrying out their duties at school. Culture affects the state of the school environment as in terms of interacting with colleagues and relating in terms of comfort. Therefore, the strengthening of organizational culture is very necessary in the working environment of teachers at elementary schools in PuloGadungDistrict.

Thus, when organizational culture strengthens then found the working environment that is conducive, based on the description has been clear that organizational culture has a direct positive influence on the work environment. Here is the final model of hypothetical research,

\section{Conclusion}

Based on the calculation and testing of research hypotheses, it can be concluded, 1) organizational culture has a direct positive influence on OCB. That is, the strengthening of organizational culture resulted in an increase in OCB of elementary schools teachers in Pulo Gadung District, 2) work environment have a direct positive influence on OCB. That is, the accuracy of a conducive working environment resulted in an increase in OCB of elementary schools teachers in Pulo Gadung District, 3) organizational culture has a direct positive effect on the work environment.It means that the strengthening of organizational culture

Volume 6 Issue 12, December 2017 
resulted in the accuracy of the work environment to be conducive to SDN teachers in Pulo Gadung District. Based on this research, it is concluded that there is influence of organizational culture and work environment to OCB.

\section{References}

[1] Kompas Newspaper "Quality of Human Resources (Article)" Friday, April 7, 2017.

[2] Syarif Hidayat. Profession Education "Theory and Practice in the Era of Autonomy". (Tangerang: PT Pustaka Mandiri, 2012).

[3] Interview with Head of Pulo Gadung District Executive Unit Mr. Zainal Arifin, February 8, 2017, at Kasatlak Office, Pulo Gadung District.

[4] Ul Mujeeb Ehtesham, Tahir Masood Muhammad, Shakil Ahmad Muhammad. Relationship between Organizational Culture and Performance Management Practices. Journal of Competitiveness. Issue 4/2011 .http: //www.cjournal.cz/files/77. (Accessed, November 28, 2017)

[5] Ruchi Jain, Surinder Kaur. "Impact Of Work Environment On Job Satisfaction". International Journal of Scientific and Research Publications, Volume 4, Issue 1, January 2014. 1 ISSN 2250-3153. http://www.ijsrp.org/research-paper-0114/ijsrpp2599.pd. (accessed November 29, 2017),

[6] Edwin Locke. Hand Book of Principles of Organizational Behavior. (New York : John Wiley \& Sons, 2009), h. 183.

[7] Nagpur Bhabani P Rath. "Influence of oganizational culture on OCB: A Study Three-Sector Study: Jagannath Mohanty, Institute of Management Technology, Berhampur University, Berhampur. Global Journal Of Business Research. Vol. 6, No. 1, pp. 65-76, 2012. SSRN's eLibrary.https: //papers.ssrn.com/sol3/papers.cfm? Abstract_id = 1946000. (Accessed November 29, 2017).

[8] Chevanese Samms Brown, Shetia Butler Lamar, Ulysses Brown, Savannah State University "International Journal of Education Research Factor Influencing Organizational Citizehsihip Behavior and Academic Motivation In The Classrom. Spring2015, Vol. 10 Issue 1, p67-77. 11p. Ebsco Public Libraries. https://www.ebsco.com/who-we-serve/public-libraries. (accessed May 20, 2017).

[9] Robbins and Timothi A. Jugde. Organizational Behavior. (New Jersey: Pearson Educational, 2011)

[10]Quick and Nelson. Principles Of Organizational Behavior "Realities and Challenges 8 Ed". (SouthWestern :Nelson Education,2013)

[11] Schermerhorn, Osbron, Uhl-Bien dan Hunt. Organizational Behavior. (United States : International Student Version, 2012).

[12] Stephen P.Robbins, David A DeCenzo dan Marry Coulter. Fundamentals Of Management. (New Jersey : Pearson, 2011)

[13] Mc Shane. Organizational Behavior. (New York : Mc Graw Hill Education, 2013) 